\title{
Revista Brasileira de Enfermagem REBEn \\ Gerentes do território na Estratégia Saúde da Família: análise e perfil de necessidades de qualificação
}

\author{
Managers of territory in the Family Health Strategy: analysis \\ and profile of qualification necessities \\ Gerentes de teritorio en la Estrategia Salud de la Familia: análisis \\ y perfil de las necesidades de calificación
}

\section{Francisco Rosemiro Guimarães \\ Ximenes Neto}

Enfermeiro Sanitarista. Mestre em Saúde Pública. Docente da Universidade Estadual do Vale do Acaraú, Sobral, CE. Membro do Grupo de Estudos e Pesquisas Vida e Trabalho da Universidade Estadual do Ceará (UECE).

\section{José Jackson Coelho Sampaio}

Médico. Doutor em Medicina Social. Professor Titular e Diretor do Centro de Ciências da Saúde da Universidade Estadual do Ceará, Fortaleza, CE. Líder do Grupo de Estudos e Pesquisas Vida e Trabalho da UECE.

Dados empíricos extraídos da dissertação de Mestrado intitulada "Gerenciamento no Território da Estratégia Saúde da Família: análise do processo de trabalho dos gerentes" do Programa de Pós-Graduação em Saúde Pública, da Universidade Estadual do Ceará-UECEI Fortaleza/Brasil, defendida em 28 de junho de 2007.

\section{RESUMO}

O estudo objetivou elaborar o perfil sócio-demográfico e educacional dos gerentes de território da ESF e identificar os tipos de qualificação ou processo de educação permanente que tem ou estão inseridos os gerentes, o desenvolvimento científico-cultural dos mesmos. A pesquisa é do tipo exploratório-descritiva, realizada em Sobral - Ceará, com 28 gerentes de território da Estratégia Saúde da Família no período de novembro de 2006 a junho de 2007. Para coleta de dados foi utilizado um questionário e uma entrevista semi-estruturada. O perfil sócio-demográfico dos gerentes mostra que: $57,2 \%$ estão na faixa etária de 25 a 34 anos; $92,9 \%$ são do sexo feminino; $78,6 \%$ são casados; $57,2 \%$ têm renda mensal na ESF de R\$ $1.800,00$ a 2.000,00; $100 \%$ são enfermeiros; $71,4 \%$ possuem Especialização na modalidade de Residência Multiprofissional em Saúde da Família e $57,1 \%$ apresentam necessidade de qualificação em gestão em saúde e gestão de pessoas. Sugere-se que a Secretaria Municipal da Saúde e Ação Social poderá estabelecer as atribuições dos gerentes e avaliar o perfil dos gerentes durante a nomeação, e confrontálo com o perfil que o sistema exige.

Descritores: Programa Saúde da Família; Organização e administração; Enfermagem em saúde pública;

\section{ABSTRACT}

The study aimed at elaborating the socio-demographic and educational profile of managers of territory of the Family Health Strategy and to identify the qualification types or process of permanent education that the managers have or to the ones that are inserted, the cultural- scientific development of them. The investigation is of exploratory-descriptive type, carried out in Sobral - Ceará, with 28 managers of territory of the Strategy of Health of the Family in the period of November of 2006 to June of 2007. For the collection of data it was used a questionnaire and a semi-structured interview. The socio-demographic profile of the managers shows that $57.2 \%$ are in the age group from 25 to 34 years; $92.9 \%$ are of the feminine sex; $78.6 \%$ are married; $57.2 \%$ have a monthly wage in the ESF of $R \$ 1,800.00$ to 2,000.00, $100 \%$ are male nurses; $71.4 \%$ possess specialization in the modality of Multi-Professional Residence in Health of the Family; $57.1 \%$ present qualification necessity in administration in health and human people's administration. It is suggested that the Municipal and Social Action Secretary of Health will be able to establish the attributions and to evaluate the profile of the managers during the nomination, and to confront them with the profile that the system demands.

Descriptors: Family Health Program; Organization and administration; Public health nursing.

\section{RESUMEN}

El estudio tiene como objetivo elaborar el perfil sociodemográfico y educacional de los gerentes de territorio de la Estratégia Salud de la Familia e identificar los tipos de calificación o proceso de educación permanente que los gerentes tienen o al que están inseridos, el desarrollo científico- cultural de los mismos. La investigación es de tipo descriptiva-exploratoria, realizado en Sobral - Ceará, con 28 gerentes de territorio de la Estrategia de Salud de la Familia en el periodo de noviembre de 2006 a junio de 2007. Para la colección de datos fue utilizado un cuestionario y una entrevista semiestructurada. El perfil socio-demográfico de los gerentes muestra que $57,2 \%$ están en el grupo de edad de 25 a 34 años; $92,9 \%$ son del sexo femenino; $78,6 \%$ son casados; $57,2 \%$ tienen un salario mensual en la ESF de $R \$$ $1.800,00$ a 2.000,00; $100 \%$ son enfermeros; $71,4 \%$ poseen Especialización en la modalidad de Residencia Multi-Profesional en Salud de la Familia; e 57,1\% presentan necesidad de calificación en gestión en salud y gestión de personas, respectivamente. Se sugiere que la Secretaria Municipal de Salud y Acción Social podrá establecer las atribuciones de los gerentes y evaluar el perfil de los gerentes durante el nombramiento, y confrontarlos con el perfil que el sistema exige.

Descriptores: Programa Salud de la Familia; Organización y administración; Enfermería de salud pública.

Ximenes Neto FRG, Sampaio JJC. Gerentes do território na Estratégia Saúde da Família: análise e perfil de necessidades de qualificação. Rev Bras Enferm 2007 nov-dez; 60(6): 687-95. 


\section{IINTRODUÇÃO}

O Programa Saúde da Família-PSF, institucionalizado em 1994 pelo Ministério da Saúde do Brasil, foi criado com o intuito de reverter o modelo assistencial vigente, que era o hegemônico, centrado em ações de cura e no ato médico.

Ainstitucionalização do PSF de acordo com autores ${ }^{(1)}$, inicialmente, focalizava grupos populacionais relativamente excluídos pelo modelo de atenção hegemônico e buscava a efetivação daAtenção Primária à Saúde-APS.

O PSF rapidamente cresceu, tanto em números de equipes implantadas em todo o país, quanto na redução de indicadores de morbidade e mortalidade, e conseqüente, melhoria de indicadores de qualidade de saúde, a exemplo da cobertura vacinal, de pré-natal dentre outros. Com esse avanço, o PSF deixa de ser um programa e passa a uma política governamental estratégica da APS, denominada de Estratégia Saúde da Família-ESF(2). Germano et $\mathrm{a}^{\left({ }^{(3)}\right)}$ afirmam que a ESF busca mudar "paradigmas cristalizados historicamente, incorporando um novo olhar, um novo pensar e um novo fazer, no qual o foco passe a ser a saúde e não a doença; a família e não o indivíduo; a equipe e não o médico", numa lógica de trabalho intersetorial e não isolado, unidisciplinar.

Daí a importância que a ESF tem na mudança do modelo assistencial, com o fim da melhoria da qualidade de vida. De acordo com Rosa e Labate ${ }^{(4)}$ "a busca de novos modelos de assistência decorre de um momento históricosocial, onde o modelo tecnicista/hospitalocêntrico não atende mais à emergência das mudanças do mundo moderno e, conseqüentemente, às necessidades de saúde das pessoas". Por isso, o "PSF torna-se estratégia significativa para a mudança do modelo assistencial visando a qualidade de vida da comunidade".

A universalização da atenção à saúde, garantida pelo SUS e, conseqüentemente, pela ESF, vem proporcionado que milhões de brasileiros indígenas, pardos, pretos, miseráveis ou ricos, afortunados ou não, tenham acessibilidade e acesso a ações e serviços saúde. A ESF é o modelo de atenção à saúde, que vem permitindo a maior inclusão social, política e econômica a uma política sanitária. Atualmente, a ESF, segundo o Ministério da Saúde, assiste em todo Brasil, 85.737 .789 milhões de sujeitos, com uma cobertura de 46,19\% da população, assistidos por 221.854 ACS e 26.729 equipes de saúde da família( ${ }^{(5)}$.

No entanto, o processo de construção do SUS e, conseqüentemente, 0 desenvolvimento da ESF, vêm pautando nas discussões dos formuladores de políticas, gestores ou não, que papel e perfil devem ter os gerentes de serviços de saúde; quais suas necessidades de qualificações; que ações os mesmos devem ser responsabilizados; e, como esses gerentes devem atuar frente às adversidades dos serviços.

A Norma Operacional Básica-NOB - SUS 01/19966, trouxe uma distinção entre gestão e gerência, sendo a primeira a atividade/responsabilidade de dirigir um sistema de saúde nas diferentes esferas de governo, exercendo as funções de coordenação, articulação, negociação, planejamento, acompanhamento, controle, avaliação e auditoria; e a segunda "como sendo a administração de uma unidade ou órgão de saúde - ambulatório, hospital, instituto, fundação dentre outros -, que se caracteriza como prestador de serviços ao Sistema". Mesmo com a distinção conceitual dos papéis gerenciais, tanto de sistema como de serviço de saúde, ainda não ocorreu uma definição de atribuições para os gerentes nos diferentes níveis de atenção - primária, secundária e terciária -, fato que tem a contribuído com uma absorção excessiva de atividades por tais profissionais, e em conseqüência, comprometido os produtos finais, que é o gerenciamento do processo de cuidar e a qualidade da atenção à clientela, de forma humanizada.

Apesar de a NOB - SUS 01/1996 ${ }^{(6)}$ introduzir de forma sistemática uma concepção de gestão e gerência - que para a época era um avanço -, atualmente, serve somente como normalizadora, se analisarmos as novas nuances da gestão contemporânea, principalmente, no que concerne à gestão participativa, em que o poder gerencial se dilui diante da coletividade, fortalecendo a corporação. moldando-se fortemente na participaçante da col.etivaes dos serviços

Assim, o presente estudo objetivou elaborar o perfil sócio-demográfico e educacional dos gerentes de território da ESF e identificar os tipos de qualificação ou processo de educação permanente que tem ou estão inseridos os gerentes, o desenvolvimento científico-cultural dos mesmos.

\section{METODOLOGIA}

A pesquisa é do tipo exploratório-descritiva. O estudo foi realizado no território municipal de Sobral - Ceará. Sobral hoje representa para o Sistema Estadual e Nacional de Saúde, uma referência em ESF, devido a sua cultura organizacional, que apresenta solidez, pois utiliza como método administrativo, a gestão de coletivos, de modo democrático e participativo. Aatenção mostrase voltada aos cuidados sócio-sanitários das famílias, sujeitos e comunidades.

Os sujeitos desta pesquisa foram constituídos por 28 gerentes de território na ESF, estando os mesmos, assim distribuídos geograficamente 14 na zona urbana e igual número na zona rural. A pesquisa foi realizada no período de novembro de 2006 a junho de 2007.

Para a coleta de dados referente às variáveis do perfil, a formação profissional, os tipos de qualificação estão inseridos os gerentes e 0 desenvolvimento científico-cultural dos mesmos, foi utilizado um questionário composto por perguntas abertas e fechadas e uma entrevista semi-estruturada para coleta das falas que reforçam os resultados quantitativos.

Os questionários foram aplicados, durante a roda de gestão dos gerentes com a Coordenação Municipal da ESF, no mês de novembro de 2006. Os questionários foram entregues aos sujeitos, em seguida, apresentados os objetivos da pesquisa e os seus direitos, com o intento de promover os princípios éticos e legais da mesma. Após os devidos esclarecimentos, os sujeitos assinaram o Termo de Consentimento Livre e Esclarecido. No momento da coleta dos dados, por meio dos questionários, estavam ausentes 11 gerentes, sendo que o referido instrumento foi entregue aos seus representantes na roda, para que os mesmos preenchessem e enviassem à Escola de Saúde da Família Visconde de Sabóia-EFSFVS. Foi orientado que os questionários fossem enviados em envelope lacrado, para manter 0 sigilo das informações. Antes da aplicação do questionário foi realizado um pré-teste, no início do mês de novembro de 2006, com três gerentes, para sua validação. As entrevistas foram realizadas por meio do agendamento prévio, com hora marcada, nos Centros de Saúde da Família, como também nos espaços da EFSFVS, de modo que preservasse a privacidade dos gerentes. As cinco primeiras entrevistas foram gravadas, com o consentimento dos sujeitos. Porém, nove dos entrevistados não aceitarem a gravação das entrevistas; por conta disso, optamos por não gravar as demais, por perceber que estes estavam ficando inibidos. Para preservação dos sujeitos da pesquisa, foram utilizados nomes marianos.

Para a realização do estudo foi buscada, inicialmente, a permissão da Secretaria da Saúde e Ação Social do Município de Sobral-CE, por meio do Núcleo de Estudos e Pesquisas em Saúde-NEPS, quando foi encaminhado 0 Protocolo de Pesquisa, sendo este analisado e, em seguida, deliberado em favor da realização da pesquisa; por conseguinte, o Protocolo de Pesquisa foi encaminhado ao Comitê de Ética e Pesquisa da Universidade Estadual do Ceará-UECE, sendo o mesmo aprovado. O campo da pesquisa foi regido pela Resolução No 196/1996 do Conselho Nacional de Saúde-CNS, que se refere aos aspectos éticos e legais da pesquisa envolvendo seres humanos.

\section{RESULTADOS E DISCUSSÃO}

\subsection{Perfil Sócio-Demográfico e Educacional dos Gerentes}

A Tabela 1 apresenta o perfil sócio-demográfico dos gerentes, que se concentra na faixa etária de 25 a 34 anos, no sexo feminino, no estado civil casado e na categoria profissional enfermeiro/a.

Observa-se na Tabela 1 que, dos 28 gerentes, 20 já se encontram acima 
Tabela 1. Distribuição dos Gerentes do território da Estratégia Saúde da Família por idade, sexo, estado civil e profissão. Sobral - CE, nov. 2006.

\begin{tabular}{lcc}
\hline VARIÁVEIS & $\mathbf{N}^{\circ}$ & $\%$ \\
\hline Idade (anos) & & \\
$25-29$ & 8 & 28,6 \\
$30-34$ & 8 & 28,6 \\
$35-39$ & 6 & 21,4 \\
40 e mais & 6 & 21,4 \\
Total & 28 & 100,0 \\
Sexo & & \\
Feminino & 26 & 92,9 \\
Masculino & 2 & 7,1 \\
Total & 28 & 100,0 \\
Estado Civil & & \\
Casada/o & & \\
Solteira/0 & 22 & 78,6 \\
Com companheiro fixo & 5 & 17,8 \\
Total & 1 & 3,6 \\
Profissão & 28 & 100,0 \\
Enfermeiro & & \\
Total & 28 & 100,0 \\
& 28 & 100,0 \\
\hline
\end{tabular}

dos 29 anos de idade, o que relativiza, neste caso, a idéia de a ESF estar se constituindo como inserção inicial no mercado de trabalho. Mas, é significativa a proporção dos que assim o fazem, pois oito se encontra na fase adulta jovem, entre 25 e 29 anos.

Antes daESF, a formação para o setor saúde era restritamente direcionada à Clínica, e, conseqüentemente, o campo de trabalho que lhe advinha era 0 do território de um hospital, com áreas bem definidas de enfermarias e leitos. Com a tentativa de reversão do modelo de atenção hegemônico hospitalocêntrico e medicalocêntrico -, e a construção do campo daAPS como estratégia, atualmente os egressos dos cursos de graduação em saúde, especialmente de Enfermagem, Medicina e Odontologia, têm buscado como primeiro emprego a ESF. Tal panorama poderia influenciar a mudança na lógica do trabalho em saúde, atualmente dirigida à promoção da saúde numa perspectiva da concepção de saúde como qualidade de vida, e não como ausência de doença, diante de ações como a produção social de saúde.

Pesquisa realizada em 1999, por Machado (7), intitulada "Perfil dos Médicos e Enfermeiros do Programa Saúde da Família no Brasil", na variável faixa etária até 29 anos, prevaleceu o seguinte: no Ceará houve uma predominância de $48,66 \%$ dos enfermeiros; no Nordeste, $38,55 \%$ e no Brasil $36,6 \%$. No caso dos médicos, no Brasil 19,1\% apresentavam a mesma faixa etária; no Nordeste o percentual aumenta para $22,69 \%$, e no Ceará $28,93 \%$. Em pesquisa desenvolvida por Vanderlei(i), no Estado do Maranhão com gerentes de UBS, predominou o sexo feminino - 100\% dos sujeitos.

A pesquisa de Machado ${ }^{(7)}$ demonstrou que os enfermeiros na ESF tem a seguinte distribuição: Ceará - 88,13\%; Nordeste - 91,4\%; e no Brasil $90,9 \%$. Em pesquisa realizada por Fracolli e Egry ${ }^{(9)}$ no município de Marília - São Paulo, acerca do processo de trabalho dos gerentes de UBS, 100\% dos sujeitos eram enfermeiras.

O feminino sempre foi muito forte na Enfermagem Brasileira, assim como na enfermagem mundial. No caso da Enfermagem no Brasil, seu ensino, desde a gênese, teve como objetivo o preparo teórico e prático, ou seja, a formação de enfermeiras. De acordo com Lima ${ }^{(10)}$, as mulheres enfermeiras "sempre existiram, desde tempos imemoriais, circulando de casa em casa, de cidade em cidade, cuidando de outras mulheres, crianças, idosos, deficientes e pobres. Esses cuidados incluíam fazer partos, assistir recémnascidos, ensinar higiene, fazer curativos e oferecer apoio, entre outras atividades".

Em determinado momento na história da enfermagem, no percurso de pré-profissional até a enfermagem moderna atual, o perfil das enfermeiras era de mulheres do baixo clero ou da nobreza, mas com votos de obediência, bondade, abnegação e humildade, com o intuito de cuidar dos doentes e dos mais necessitados.

A Organização Mundial da Saúde-OMS ${ }^{(11)}$ afirma que em quase todos os países as mulheres constituem a vasta maioria do pessoal de enfermageme parteira. Em todas as partes a Enfermagem é trabalho de mulher e tem as mesmas características de outras ocupações em que predomina a mulher: baixa remuneração, condição inferior, deficientes condições de trabalho, escassas perspectivas de promoção e formação deficiente.

Quanto a esta lógica da feminilização própria da enfermagem, autor ${ }^{12}$ afirma que a sociedade delimita com bastante precisão, os campos em que pode operar a mulher, da mesma forma como escolhe os terrenos em que pode atuar o homem.

Entendemos que o cargo de gerente não deve ser centrado nos profissionais de enfermagem e em mulheres, mas sim na competência individual e coletiva de gerenciar, a partir da análise do perfil profissional, com base em competências.

No caso de $100 \%$ dos gerentes serem enfermeiros talvez se deva ao fato de que os mesmos tenham uma grande apropriação dos saberes e práticas nos campos da Saúde Pública e da Saúde Coletiva, em especial da APS. Outro aspecto determinante a ser considerado é o longo tempo de atuação dos enfermeiros em um mesmo território, proporcionando um amplo conhecimento deste e o estabelecimento de vínculo com as famílias e comunidade. Um terceiro aspecto provavelmente se detenha ao baixo valor pago pelo cargo de gerente, como fica evidenciado na Tabela 2, e, sendo 0 mercado de trabalho em enfermagem cerceado permanentemente por uma política de baixos salários, talvez justifique a maior adesão de enfermeiras ao cargo. O quarto aspecto pode está associado à condição social da mulher no mercado de trabalho que, historicamente, vem sofrendo exclusão e percebendo um salário inferior ao do homem, quando na execução de uma mesma atividade.

A Tabela mostra uma predominância dos gerentes com renda entre $\mathrm{R} \$$ $1.800,00$ e 2.300,00, o equivalente a US $\$ 829,49$ e 1.013,82. O salário dos gerentes é equivalente ao dos enfermeiros assistenciais, diferenciando-se apenas a gratificação do cargo comissionado. Na pesquisa realizada por Machado ${ }^{7}$, em 1999 a renda mensal média declarada do enfermeiro era de US\$1.123, ao comparar com os valores pagos em Sobral, o salário no município é menor, isto sem consideramos as perdas salariais devido à inflação e outros do período. Avariação na renda mensal dos gerentes ocorre em detrimento àárea de atuação - os que atuam na zona rural possuem um incentivo - e aos plantões. 
Tabela 2. Distribuição dos Gerentes do território da Estratégia Saúde da Família por renda. Sobral-CE, 2006.

\begin{tabular}{|c|c|c|}
\hline RENDA & $\mathrm{N}^{\circ}$ & $\%$ \\
\hline \multicolumn{3}{|c|}{ Renda Mensal* na ESF (R\$) } \\
\hline $1.800,00$ a $2.000,00$ & 16 & 57,2 \\
\hline $2.200,00$ a $2.300,00$ & 10 & 35,7 \\
\hline$>2.300,00$ & 2 & 7,1 \\
\hline Total & 28 & 100,0 \\
\hline \multicolumn{3}{|c|}{ Valor da Gratificação do Cargo de Gerente (R\$) } \\
\hline 100,00 & 2 & 7,1 \\
\hline 200,00 & 24 & 85,7 \\
\hline 700,00 & 1 & 3,6 \\
\hline Não respondeu & 1 & 3,6 \\
\hline Total & 28 & 100,0 \\
\hline \multicolumn{3}{|c|}{ Outras atividades que gerem renda } \\
\hline Não & 23 & 82,1 \\
\hline Sim & 5 & 17,9 \\
\hline Total & 28 & 100,0 \\
\hline \multicolumn{3}{|l|}{ Atividades } \\
\hline Plantões & 3 & 10,7 \\
\hline Enfermeira da SESA & 1 & 3,6 \\
\hline Não respondeu & 1 & 3,6 \\
\hline
\end{tabular}

Tabela 3. Formação profissional dos gerentes do território da Estratégia Saúde da Família, segundo a formação profissional. Sobral-CE, 2006.

\begin{tabular}{lcc}
\hline FORMAÇÃo & $\mathbf{N}^{\circ}$ & $\%$ \\
\hline Tempo de Graduado (anos) & 11 & 39,2 \\
$3-5$ & 5 & 17,9 \\
$6-8$ & 7 & 25,0 \\
$9-11$ & 5 & 17,9 \\
12 e mais & 28 & 100,0 \\
Total & & 31,2 \\
Pós-Graduação & 9 & 14,3 \\
Residência em Saúde da Família & 4 & 14,3 \\
Residência em Saúde da Família + Educação Profissional em Saúde: Enfermagem & 10,7 \\
Residência em Saúde da Família + Especialização em Enfermagem Obstétrica & 4 & 7,1 \\
Residência em Saúde da Família + Saúde Pública & 3 & 3,6 \\
Especialização em Saúde da Família & 2 & 3,6 \\
Especialização em Saúde da Família + Especialização em Enfermagem Obstétrica & 1 & 3,6 \\
Especialização em Enfermagem Obstétrica & 1 & 3,6 \\
Especialização em Saúde Pública & 1 & 7,1 \\
Especialização em Enfermagem do Trabalho & 1 & 100,0 \\
Não possui & 2 & $\mathbf{2 8}$ \\
Total & & 3 \\
\hline
\end{tabular}

Karl Marx, em sua obra O Capital(13) afirma que: 0 salário do operário aparece como o preço do trabalho, soma determinada de dinheiro paga em troca de uma quantidade determinada de trabalho. Fala-se em valor do trabalho e se dá à sua expressão monetária o nome de preço necessário natural. Fala-se igualmente em valores comerciais do trabalho, quer dizer, em preços superiores ou inferiores que oscilam em torno do preço necessário.

Marx ${ }^{(13)}$ afirma ainda, que o "salário é determinado pelo preço dos meios de subsistência dos operários". Os valores percebidos pelo cargo de gerente indicam tratamento idêntico ao que o capital oferece ao trabalho operário. Os valores são irrisórios e incompatíveis com o cargo de gerente de território, pois incorpora a responsabilidade de administrar parte do Sistema Municipal de Saúde, envolvendo gestão de pessoas, de recursos e de produção de saúde de toda uma coletividade, além da gestão do cuidado a grupos de sujeitos dependentes dos cuidados de terceiros.

Mais de um século depois de Marx, observamos que a remuneração do trabalho ainda representa apenas o valor dos meios de subsistência necessários à conservação fisiológica mínima da vida do operário, ou melhor, atualizando, do profissional de saúde. Marx ${ }^{(13)}$ afirma ainda que, a massa desses meios de subsistência, ainda que sua forma possa mudar, deve ser considerada, numa certa época e numa sociedade determinada, como uma grandeza constante. O que muda é o valor dessa massa. Dois outros fatores entram na determinação do valor da força de trabalho. De uma parte, as despesas necessárias ao seu desenvolvimento e que mudam de acordo com o modo de produção; de outra, sua diferença específica, proveniente de que ela é masculina e feminina, adulta ou adolescente .

Contudo, a complexidade que é o gerenciamento do território na ESF, exige um reconhecimento profissional e financeiro por parte da gestão municipal, além de um Plano de Carreiras, Cargos e Salários-PCCS capaz de assegurar os direitos e garantias trabalhistas, como férias integral-incluindo o terço de férias salarial,$- 13^{\circ}$ salário, licença a maternidade e paternidade dentre outros. No mercado capitalista, quanto maior a competência do gerente, maior seu salário, e quanto maior a motivação, maior é a produtividade. A desvalorização de um cargo ou função de relevância social e complexidade técnica indica uma lógica locorregional de mercado que contradiz a lógica maior de remuneração do sistema, além de retirar do cenário uma fonte de motivação.

A Tabela 3 apresenta o tempo de formação em enfermagem e a pósgraduação Lato Sensu, basicamente focada na Residência e/ou em Especialização, em Saúde da Família e em Saúde Pública, isto é, formações próprias do campo. 
Aleitura da Tabela 3 possibilita-nos identificar parcela dos gerentes - 11 com três a cinco anos de formado. Machado ${ }^{7}$ em seu estudo demonstrou que $43,1 \%$ dos enfermeiros tinham até quatro anos de formado. Por outro lado, em pesquisa realizada com Enfermeiros gerentes de UBS no Rio de Janeiro, no ano de 2003, 52\% apresenta um tempo de formado entre 16 - 20 anos ${ }^{(14)}$. A população investigada apresenta identidade com aquela da pesquisa de Machado. Mas o menor tempo de formatura entra em contradição com a predominância do grupo em faixa etária maior, o que leva-nos a acreditar numa formação mais tardia, na região do campo do presente estudo.

No caso de Sobral, Ximenes Neto e Ribeiro ${ }^{(15)}$ referem que o município, apresenta um contingente de trabalhadores da saúde - de enfermagem bastante novo, ou seja, com pouco tempo de formação profissional atuando naAPS do município. Torna-se claro que os profissionais novos estão sendo melhor posicionados no Município de Sobral pela ESF, devido aos novos currículos que enfatizam a capacitação para o processo de atuação na atenção primária, como suporte para a ação profissional que contribui para a melhoria da qualidade de vida da população.

Quanto à educação dos profissionais de saúde, a $\mathrm{OMS}^{(16)}$ afirma que a mesma tem sido amplamente criticada por não estar voltada às necessidades de saúde da sociedade. Amaioria dos profissionais tem uma formação densa no campo biomédico e clínico, mas pequena formação em Ciências Sociais e Humanas, o que reduz suas habilidades em manejar questões políticas, sociais, culturais e econômicas, exigidas pela gerência. São escassas as oportunidades de aprender como direcionar os poderes sociais, econômicos e políticos que interferem no setor saúde. O texto da OMS complementa, afirmando que as instituições responsáveis pela capacitação dos profissionais de saúde estão distantes dos espaços de tomada de decisões, acerca da provisão dos serviços e das políticas de saúde.

Este estudo mostra que 20 gerentes possuem Especialização na modalidade de Residência Multiprofissional em Saúde da Família, dentre estes 12 possuem mais de um Certificado de Especialização. O gerente que é possuidor de formação na modalidade Residência em Saúde da Família, caracterizada pelo ensino em serviço e pela grande carga horária prática, poderá vir a ter mais clareza do seu objeto de trabalho no campo da Saúde da Família, Saúde Pública, Saúde Coletiva, Planejamento, Educação Popular e Promoção da Saúde.

$\mathrm{Na}$ pesquisa de Machado(7), 40,03\% dos enfermeiros tinham Especialização em Saúde Pública; 15,36\% em Enfermagem Obstétrica;
12,25\% Médico-Cirúrgica; 4,90\% Enfermagem do Trabalho; e somente 2,2\% Especialização em Saúde da Família.

Em Sobral, dos 28 Gerentes, 16 têm mais de uma especialização. Isto ocorre devido aos grandes investimentos que o município tem empreendido para a educação na saúde de sua equipe de trabalhadores, como também a oportunidade e o fácil acesso à universidade local.

Os profissionais da saúde e de outros setores têm buscado uma superespecialização, talvez influenciado pelo capitalismo, que exige trabalhadores com amplo conhecimento e polivalentes, para manter-se no mercado, levando-os a uma alienação trabalhista.

A atuação na ESF exige uma diversidade de saberes e práticas em áreas relacionadas à gestão sanitária, ao cuidado de famílias, sujeitos e populações, ao manejo das determinações e conseqüências sociais, ao território de atuação, às concepções e práticas de saúde. Tais conhecimentos, muitas vezes, não são oferecidos durante a formação na graduação, levando os profissionais a se especializarem em várias áreas para dar conta de um processo de trabalho vastíssimo na ESF.

A debilidade dos currículos da graduação no que concerne à atuação na APS tem motivado a superespecialização ou especialização múltipla. A superespecialização ou especialização múltipla para atuação no território da ESF tem fomentado um dilema de identidade; levado os diversos profissionais a uma indefinição de papéis, influenciados pela formação de especialista; além do trabalho fragmentado e precarizado.

\subsection{Qualificação e Educação Permanente-EP}

A qualificação dos trabalhadores de saúde, principalmente os da ESF, é de fundamental necessidade, devido aos avanços teóricos, organizacionais, tecnológicos e políticos ocorridos e a diversidade, tanto do campo da atenção, como da gestão no território, o que impõe, diariamente, novas situações a serem enfrentadas. A Educação Permanente em Saúde permite a resignificação do processo de trabalho, por sua prática ser desenvolvida em serviço, e a apropriação efetiva do território, com suas necessidades de saúde sentidas ou não. A Tabela 4 apresenta a qualificação recebida pelo gerente durante sua atuação. TABELA4

Dos gerentes, 27 não receberam qualificação no ato da nomeação, situação explicitada na fala da gerente Maria Estrela do Mar: Eu não tive escolha! Surgiu a vaga, então fui colocada, fui jogada, não passei por treinamento de nada [...], tive que aprender trabalhando.

Tabela 4. Histórico de qualificação dos gerentes do território da Estratégia Saúde da Família. Sobral-CE, 2006.

\begin{tabular}{lrr}
\hline \multicolumn{1}{c}{ QUALIFICAÇÃo } & $\mathrm{N}^{\circ}$ & $\%$ \\
\hline Qualificação recebida no ato da nomeação & 27 & 96,4 \\
Não & 1 & 3,6 \\
Sim & 28 & 100,0 \\
Total & & \\
Qualificação/EP vivenciado pelo Gerente & 23 & 82,1 \\
Organização de Serviço & 12 & 42,9 \\
Hanseníase & 10 & 3,6 \\
Preceptoria & 8 & 28,6 \\
Pré-natal & 8 & 28,6 \\
Biossegurança & 7 & 25,0 \\
Saúde da Mulher & 5 & 17,9 \\
Abordagem Sindrômica em DST & 4 & 14,3 \\
Tuberculose & 3 & 10,7 \\
Gerenciamento em Saúde Reprodutiva & 3 & 10,7 \\
Saúde da Criança & 3 & 7,1 \\
Saúde do Adolescente & 2 & 7,1 \\
Hipertensão Arterial Sistêmica e Diabetes mellitus & 2 & 7,1 \\
Prevenção do Câncer Cérvico-Uterino & 2 & 3,6 \\
Qualificação sobre Enfermagem & 1 & 3,6 \\
Planejamento Familiar & 1 & 3,6 \\
Eventos em geral & 1 & \\
\hline
\end{tabular}

Rev Bras Enferm, Brasília 2007 nov-dez; 60(6): 687-95. 
No caso dos gerentes da ESF do município de Sobral, era imprescindível a qualificação dos mesmos ao assumirem o cargo, em virtude de ascenderam profissionalmente de uma função assistencial para uma gerencial. Toda e qualquer empresa/serviço que tenha a missão e/ou meta de um padrão de qualidade, deve possuir em seu quadro de pessoal, gestores e/ou gerentes, com um perfil de extrema competência e qualificados.

No que concerne à qualificação e/ou processo de educação permanente que o gerente tenha vivenciado, há o predomínio de temas voltados para a atenção à saúde. Isto se deve ao fato de apenas sete gerentes atuarem exclusivamente na prática gerencial. Dentre os temas, é destacado a organização de serviço, tema vivenciado a partir da preceptoria de enfermagem da EFSFVS. Ressaltamos que o coletivo de gerentes em Sobral não está inserido em processo de educação permanente próprio ao seu processo de trabalho gerencial. Na Tabela 5, os gerentes apresentam um menu de necessidades de qualificação centrado na gestão em saúde, de pessoas, no planejamento, na análise de custos em saúde e na saúde do trabalhador. As principais necessidades de qualificação estão voltadas para gestão em saúde - 17 - e gestão de pessoas - 16. Dos gerentes, apenas uma não apontou suas necessidades. TABELA5

A qualificação dos gerentes, em temas que aprofundem as necessidades de planejamento, organização de sistemas e serviços, política de pessoal, planejamento e economia da saúde, contribui para o melhor desempenho destes, ampliando suas capacidades de avaliar as necessidades de saúde e a tomar decisões na gestão do território.

Segundo Vanderlei( ${ }^{(8)}$, a falta de formação específica pode ser considerada uma dificuldade para o gerenciamento, principalmente no que concerne ao "conhecimento com relação ao processo decisório" e que o desenvolvimento gerencial, definido a partir de um modelo assistencial centrado no cuidado, contribui na redefinição do papel gerencial, necessitando, porém, da adoção de uma abordagem dialética durante a análise das organizações.

É imprescindível que na atualidade, gestores e gerentes, independente do nível de gestão que estão exercendo, sejam cargos de alta gerência, média gerência ou outra, estejam inseridos num arrojado processo de educação permanente. A educação permanente no contexto da gestão do território na ESF é necessária, para que o gerente possa administrar com competência todos os processos que compreendam a gestão do cuidado em saúde e acompanhar as mudanças no sistema de saúde, a exemplo do processo de descentralização.

O processo de reforma sanitária brasileira vem demandando dos governos Municipais, Estaduais e Federais uma política de gestão do trabalho em saúde, que dê condições sociais, políticas e educacionais aos trabalhadores de saúde.

A NOB de Recursos Humanos ${ }^{(17)}$ aponta que a Educação Permanente para o processo de trabalho no SUS deve garantir a realização de atividades que promovam a educação para a Gestão do Trabalho em Saúde, incluin-dose o desenvolvimento do trabalhador; a administração de pessoal; a utilização de fontes de informações intra e extra-setoriais; a análise de sistemas de relações de trabalho; a análise de sistemas de retribuições e incentivos; a gestão dos Planos de Carreira, Cargos e Salários e os processos de negociações.

$O$ desenvolvimento científico-cultural torna-se necessário a qualquer profissional, independente de sua área de atuação ou função exercida. A instituição empregadora deve articular o fomento a este incentivo profissional e o trabalhador buscá-lo. A Tabela 6 expõe as principais dificuldades dos gerentes em realizar aprimoramento pessoal.

Tabela 5. Necessidade de qualificação dos gerentes do território da Estratégia Saúde da Família. Sobral-CE, 2006.

\begin{tabular}{lcc}
\hline \multicolumn{1}{c}{ NECESSIDADES DE QUALIFICAÇÃO } & N $^{\circ}$ & $\%$ \\
\hline Gestão & & \\
Gestão em Saúde & 17 & 60,7 \\
Gestão de Pessoas & 16 & 57,1 \\
Análise de Custos em Saúde & 6 & 21,4 \\
Dinâmicas de Grupo & 3 & 10,7 \\
Direitos Trabalhistas & 2 & 7,1 \\
Comunicação & 1 & 3,6 \\
Vigilância Sanitária & 1 & 3,6 \\
Planejamento & 1 & 3,6 \\
Segurança do trabalho & 1 & 3,6 \\
Organização de serviço & 1 & 3,6 \\
Atenção & & \\
Emergências Pré-hospitalares & 3 & 10,7 \\
Saúde Mental & 1 & 3,6 \\
Pré-natal de alto risco & 1 & 3,6 \\
\hline
\end{tabular}

Tabela 6. Dificuldades encontradas pelos gerentes para realizar aprimoramento profissional. Sobral-CE, 2006.

\begin{tabular}{lrr}
\hline \multicolumn{1}{c}{ DIFICULDADES EM FAZER APRIMORAMENTO } & $\mathrm{N}^{\circ}$ & $\%$ \\
\hline Sim & 18 & 64,3 \\
Não & 10 & 35,7 \\
Total & 28 & 100,0 \\
Dificuldades & & \\
Alto custo dos eventos científicos & 12 & 42,9 \\
Alto custo dos livros e revistas científicas & 11 & 39,3 \\
Encargos familiares & 7 & 25 \\
Falta de tempo & 7 & 25 \\
Falta de apoio institucional & 5 & 17,9 \\
Inexistência de material de estudos no trabalho & 5 & 17,9 \\
Inexistência de educação permanente no trabalho & 2 & 7,1 \\
Falta de prioridade & 1 & 3,6 \\
Falta de divulgação dos eventos científicos & 1 & 3,6 \\
Filhos pequenos & 1 & 3,6 \\
\hline
\end{tabular}


Um sistema de saúde como o brasileiro, que tem como princípio a eqüidade, e em sua Constituição Federal e na LOS - apontam a legalidade e a responsabilidade que os entes públicos federados possuem na formação dos trabalhadores na área de saúde, não deveria apontar barreiras para o aprimoramento profissional.

Dos gerentes entrevistados, 18 afirmaram apresentar dificuldades para fazer aprimoramento profissional. As dificuldades apontadas estão centradas nos aspectos próprios do financiamento e economia familiar, além do alto custo dos eventos, livros e revistas.

$\mathrm{Na}$ EFSFVS existe uma biblioteca com periódicos e um número expressivo de livros voltados para Saúde Pública, Saúde Coletiva, Gestão em Saúde, APS e pesquisa em saúde, disponíveis para os trabalhadores de saúde do sistema municipal e universidades locais de Sobral. Mas este acervo ainda não está sendo explorado pelos gerentes como deveria, como se depreende dos relatos.

Quanto aos eventos científicos, o município de Sobral libera os trabalhadores para até dois eventos anuais, com financiamento para aqueles em que o temário esteja voltado para as macropolíticas de saúde local e que apresentem temas livres acerca de relatos de experiência.

Ressaltamos que a disponibilidade de trabalhadores de saúde bem preparados vai inferir positivamente na qualidade do serviço.

3.3 Atividades desenvolvidas além do gerenciamento do território. Dos 28 Gerentes, 21 atuam na gerência do território e em ações de caráter assistencial, próprias do afazer dos Enfermeiros; e destes, 14 assumem integralmente a assistência em seu território, como apresentado na Tabela 7.

Nesta Tabela 7 as ações de caráter assistencial desenvolvida pelos gerentes, compreendem a consulta de enfermagem - à criança, ao adolescente, ao adulto, ao idoso, a mulher no ciclo gravídico-puerperal, aos portadores de tuberculose, hanseníase, Hipertensão Arterial Sistêmica-HAS, Diabetes mellitus-DM, DST/HIV -, a visita domiciliar, o trabalho com grupos, o cuidado com feridas, as ações de promoção e educação em saúde dentre outras. De acordo com Alves ${ }^{(18)}$, o enfermeiro como integrante da equipe da ESF, desenvolve ações promoção, proteção e recuperação da saúde podendo também, atuar como gerente da UBS.

A pesquisa realizada no município de Betim-MG, por Antunes ${ }^{(19)}$, sob o título $O$ Enfermeiro e a integralidade da assistência de enfermagem na rede básica do Sistema Único de Saúde, mostra que 83\% destes profissionais realizam Consulta de Enfermagem, e que $88 \%$ realizam gerência setorial, $64 \%$ gerenciam pessoal e $53 \%$ gerenciam material.

Quanto a esta situação de gerenciar o território sanitário e exercer a função de enfermeiro assistencial, a gerente Maria de Nazaré refere categoricamente:

Acho complicada essa história de gerência-assistência! É complicado por que ninguém dá conta da gama de serviços. De fazer bem, com qualidade. A gente se angustia pela disponibilidade do tempo que não tem.

A gerente refere que a sobreposição de tarefas de gerenciar e assistir, concomitantemente, pode inferir na qualidade do serviço. A situação em que o gerente atua exclusivamente nessa função é bem vivenciada pela gerente Maria do Pérpetuo Socorro:

[...] Quando passei a ser só gerente, já vi uma mudança grande, pude com isso, ter mais tempo de está observando o serviço, está mais próximo da equipe, dos servidores, de está conversando. Estáconstruindo as rotinas, olhando como estáfuncionando os setores, tendo mais controle da situação. [...] Pois a equipe cobra do gerente. Se eu não tenho tempo, como posso está discutindo? A coisa vai só passando [...].

A gerente Maria do Perpetuo Socorro aponta que o fato de atuar somente nas funções gerenciais, permite uma maior supervisão dos serviços, a construção e a utilização de ferramentas gerenciais.

Tem sido comum, na ESF, a gerência de território ou de UBS ser exercida por um profissional de saúde de sua própria equipe, que ascende por competência, perfil de liderança ou indicação. Aconstrução de um gerente com um olhar voltado para as necessidades de saúde do território e da comunidade, com uma vivência no mesmo é de singular importância, por permitir a resolução dos problemas com mais facilidade e propriedade.

Antunes ${ }^{(19)}$, quanto ao binômio gerência-atenção na prática do enfermeiro, apresenta o seguinte posicionamento: A priorização e o desenvolvimento da gerência enquanto instrumento de trabalho para alcançar a finalidade última de prestar assistência de enfermagem equiânime, resolutiva e integral conformase como uma das maiores possibilidades existentes para que o enfermeiro rompa com o seu instituído predominante: as atividades burocráticas, normalizadoras, controladoras de pessoas, e de prestação de cuidados suplementares ao ato de outros profissionais de saúde. A gerência de enfermagem pode ultrapassar isto e ser vista como um instrumento de trabalho, intercomplementar ao trabalho de outros profissionais em saúde, com a finalidade última de favorecer a vida em todas as suas manifestações e a integralidade da assistência à saúde.

Segundo Peduzzi e Ciampone ${ }^{(20)}$ o processo de trabalho do enfermeiro centrado na atenção e na gestão tem suas origens na criação da primeira escola de enfermagem, por Florence Nightingale no século XIX, em que existiam duas categorias de enfermeiras, as nurses e as ladys nurses, sendo que, às primeiras cabia o cuidado direto à clientela e as demais, o ensino $\mathrm{e}$

Tabela 7. Atividades assistenciais desenvolvidas pelos gerentes no território da Estratégia Saúde da Família. Sobral-CE, 2006.

\begin{tabular}{lcc}
\hline \multicolumn{1}{c}{ ATIVIDADES } & $\mathbf{N}^{\circ}$ & $\%$ \\
\hline Assistência de Enfermagem em Saúde da Família & 14 & 50,0 \\
Visita Domiciliar & 6 & 21,4 \\
Exame de prevenção do câncer cérvico-uterino e mama & 6 & 21,4 \\
Cuidados à criança na puericultura e com agravos & 6 & 21,4 \\
Triagem & 5 & 17,9 \\
Pré-natal & 5 & 17,9 \\
Trabalho com grupos & 4 & 14,3 \\
Supervisão e Avaliação do trabalho do ACS & 4 & 14,3 \\
Cuidados aos portadores de tuberculose & 4 & 14,3 \\
Cuidado com feridas & 3 & 10,7 \\
Cuidados aos portadores de HAS e DM & 3 & 10,7 \\
Cuidados aos portadores de hanseníase & 3 & 10,7 \\
Planejamento Familiar & 2 & 7,1 \\
Administração de vacinas & 2 & 7,1 \\
Cuidados ao adolescente & 2 & 7,1 \\
Cuidados ao adulto & 2 & 7,1 \\
Cuidados ao idoso & 2 & 7,1 \\
\hline
\end{tabular}


administração desse cuidado.

O enfermeiro, ao dividir-se no trabalho, com a responsabilidade de gerenciar o território e prestar cuidados de enfermagem a um determinado número de famílias, poderá, talvez, não conseguir dar conta dos dois como deveria, por uma questão de demanda-tempo. A principal dificuldade encontrada pelos gerentes é a conciliação das atividades de enfermagem e gerenciamento, pois, as competências gerenciais que são requeridas no território têm uma complexidade inestimável e as atribuições que são apontadas pela Política Nacional de Atenção Básica que o enfermeiro deve exercer na atenção, são vultosas. As atribuições são as seguintes:

a) realizar assistência integral - promoção e proteção da saúde, prevenção de agravos, diagnóstico, tratamento, reabilitação e manutenção da saúde aos indivíduos e famílias na USF e, quando indicado ou necessário, no domicílio e/ou nos demais espaços comunitários - escolas, associações etc. -, em todas as fases do desenvolvimento humano: infância, adolescência, idade adulta e terceira idade;

b) conforme protocolos ou outras normativas técnicas estabelecidas pelo gestor municipal ou do Distrito Federal, observadas as disposições legais da profissão, realizar consulta de enfermagem, solicitar exames complementares e prescrever medicações;

c) planejar, gerenciar, coordenar e avaliar as ações desenvolvidas pelos ACS;

d) supervisionar, coordenar e realizar atividades de educação permanente dos ACS e da equipe de enfermagem;

e) contribuir e participar das atividades de Educação Permanente do Auxiliar de Enfermagem, ACD e THD; $e$

f) participar do gerenciamento dos insumos necessários para o adequado funcionamento da Unidade de Saúde da Família-USF ${ }^{(21)}$.

A Enfermagem, historicamente, tem apresentado um grande compromisso com a Saúde Pública brasileira, e na ESF possui grande responsabilidade sanitária com as diversas ações desenvolvidas com as famílias, sujeitos e comunidades.

\section{CONSIDERAÇÕES FINAIS}

O perfil sócio-demográfico dos gerentes mostra que: $57,2 \%$ estão na faixa etária de 25 a 34 anos; 92,9\% são do sexo feminino; 78,6\% são casados; $57,2 \%$ têm renda mensal na ESF de R\$1.800,00 a 2.000,00; $85,7 \%$ recebem pelo desempenho da função de gerente uma gratificação de $\mathrm{R} \$ 200,00 ; 82,1 \%$ possuem outras atividades que gere renda. Quanto à formação e qualificação, $100 \%$ são enfermeiros; $39,2 \%$ dos gerentes têm de três a cinco anos de graduado; $71,4 \%$ possuem Especialização na modalidade de Residência Multiprofissional em Saúde da Família; 96,4\% não receberam qualificação no ato da nomeação; $60,7 \%$ e 57,1\% apresentam necessidade de qualificação em gestão em saúde e gestão de pessoas, respectivamente; $64,3 \%$ têm dificuldades de fazer aprimoramento, principalmente, por conta do alto custo dos eventos científicos, $42,9 \%$, e pelo alto custo dos livros e revistas científicas, $39,3 \%$.

O desenvolvimento científico-cultural, qualificação ou processo de educação permanente está centrado, principalmente, nas oportunidades que o município de Sobral lhes oferece, por meio da EFSFVS, que são a Residência em Saúde da Família, os momentos teórico-conceituais às terçasfeiras à tarde e as vivências de território a partir da preceptoria de enfermagem, além da participação em eventos realizados pelo município. $O$ alto custo dos eventos científicos, de livros e revistas são algumas das dificuldades dos gerentes em realizarem aperfeiçoamento profissional. Quanto à qualificação dos gerentes para o gerenciamento do território, o único componente que os mesmos estão inseridos é o da organização do serviço, vivenciado a partir da preceptoria de enfermagem.

Do coletivo de gerentes, $75 \%$ atuam como enfermeiro assistencial de determinado território, desenvolvendo cuidados a criança, ao adolescente, ao adulto, ao idoso, a mulher no ciclo gravídico-puerperal, aos portadores de tuberculose, hanseníase, Hipertensão Arterial Sistêmica-HAS, Diabetes mellitus-DM, DST/HIV -, visita domiciliar, trabalho com grupos, cuidado com feridas, ações de promoção e educação em saúde dentre outras.

Para tanto, sugere-se que a Secretaria Municipal da Saúde e Ação Social poderá:

- Estabelecer as atribuições dos gerentes.

- Avaliar o perfil dos gerentes durante a nomeação, e confrontá-lo com o perfil que o sistema exige.

- Prover o gerente de mais autonomia. É evidente a autonomia responsável na prática dos gerentes, para uma tomada de decisões no gerenciamento do território é de fundamental importância. Sabendo que a autonomia é necessária para a priorização das ações a serem desenvolvidas pela equipe durante 0 cuidado aos sujeitos, famílias e comunidades.

- Disponibilizar uma boa equipe e de todos os recursos necessários para o alcance de metas e da excelência gerencial, para o exercício de uma gerência competente.

- Deixar claro para as equipes, quais são as macropolíticas sanitárias do município e os gerentes, gerenciarem o alcance das mesmas no território.

- Avaliar o desempenho dos gerentes, pois nos territórios existem gerentes extremamente competentes e outros descontextualizados para o exercício do cargo.

- Estabelecer uma nova política gerencial de apoio aos gerentes, no que concerne ao provimento de insumos, equipamentos e manutenção, com a redução de níveis hierárquicos e de burocracia.

- Estabelecer um sistema de crédito financeiro, com base em suprimento de fundos, para os territórios, com o intuito de estar provendo pequenos serviços de manutenção e aquisição de insumos de pequeno vulto, de maneira rápida e prática, contribuindo com a redução da burocratização e 0 entrave de determinadas fases do processo de trabalho da equipe e da gestão sanitária municipal, principalmente, nos períodos de licitação e compra.

- Dar exclusividade de trabalho gerencial ao gerente, nos territórios em que os indicadores epidemiológico-sociais sejam críticos, com densa lista de necessidades sócio-sanitárias e elevada população adscrita, o gerente de território atuar exclusivamente nas ações gerenciais do território.

\section{REFERÊNCIAS}

1. Silva IZQJ, 0 trabalho em equipe no PSF: investigando a articulação técnica e a interação entre os profissionais. Interface Comun Saúde Educ 2005; 9(16): 25-38.

2. Ministério da Saúde (BR). Secretaria de Assistência à Saúde. Coordenação de Saúde da Comunidade. Saúde da Família: uma estratégia para a reorientação do modelo assistencial. Brasília (DF): Ministério da Saúde; 1997.

3. Germano RM. Capacitação das equipes do PSF: desvendando uma realidade. In: Castro JL, organizador. Gestão do trabalho no SUS: entre 0 visível e 0 oculto. Natal (RN): Observatório RHNESC/UFRN; 2007. p. 105-132.
4. Rosa WAG, Labate RC. Programa Saúde da Família: a construção de um novo modelo de assistência. Rev Latino-am Enfermagem 2005; 13(6): 1027-34.

5. Ministério da Saúde (BR). Departamento da Atenção Básica. Atenção básica e a saúde da família. [citado em 2007 jan 08]. Disponível em: URL: http://www.saude.gov.br/dab

6. Ministério da Saúde (BR). Norma operacional básica do Sistema Único de Saúde/NOB-SUS 96. Brasília (DF): Ministério da Saúde; 1997.

7. Machado $\mathrm{MH}$, coordenador. Perfil dos médicos e enfermeiros do Programa Saúde da Família no Brasil: relatório final - Região 
Nordeste. Brasília (DF): Ministério ds Saúde; 2000.

8. Vanderlei MIG. O gerenciamento na Estratégia Saúde da Família: o processo de trabalho dos gestores e dos gerentes municipais de saúde em municípios do Estado do Maranhão [tese]. Ribeirão Preto (SP): Universidade de São Paulo, Escola de Enfermagem de Ribeirão Preto; 2005.

9. Fracolli LA, Egry EY. Processo de trabalho de gerência: instrumento potente para operar nas praticas de saúde? Rev Latino-am Enfermagem 2001; 9(5): 13-8.

10. Lima MJ. O que é enfermagem. $2^{\text {a }}$. ed. São Paulo (SP): Brasiliense; 1994.

11. Organización Mundial de la Salud - OMS. La Enfermería más allá del año 2000: informe de un grupo de estudio de la OMS. Ginebra (SUI): OMS; 2000.

12. Saffiotti HIB. A mulher na sociedade de classes: mito e realidade. Petrópolis (RJ): Vozes; 1997.

13. Marx K. O capital. Rio de Janeiro (RJ): Zahar; 1982.

14. Passos JP. A utilização de indicadores na prática gerencial do Enfermeiro $\mathrm{m}$ unidades básicas de saúde na cidade do Rio de Janeiro [tese]. Universidade de São Paulo, Escola de Enfermagem; 2004.

15. Ximenes Neto FRG, Ribeiro RA. Processo de trabalho dos enfermeiros na atenção ao pré-natal da Estratégia Saúde da Família no município de Sobral. Sobral (CE): Universidade
Estadual do Vale do Acaraú; 2007.

16. Organización Mundial de la Salud-OMS. Una formación profesional mas adecuada del personal sanitario: Informe de un grupo de estudio de la OMS sobre la enseñanza orientada a la solución de problemas en las profesiones sanitarias. Ginebra (SUI): OMS; 1993.

17. Ministério da Saúde (BR). Conselho Nacional de Saúde. Documentos preparatórios para $3^{\mathrm{a}}$ Conferência Nacional de Gestão do Trabalho e da Educação na Saúde. Brasília (DF): Ministério da Saúde; 2005.

18. Alves LAAR. O perfil gerencial do enfermeiro para atuar na atenção primária em saúde. In: Santos ÁS, Miranda SMRC, organizadores. A enfermagem na gestão em atenção primária à saúde. Barueri (SP): Manole; 2007. p. 111-22.

19. Antunes MJM. Enfermeiro e a integralidade da assistência de enfermagem na rede básica do Sistema Único de Saúde [dissertação]. Belo Horizonte (MG): Universidade Federal de Minas Gerais, Escola de Enfermagem; 1996.

20. Peduzzi M, Ciampone MHT. Trabalho em equipe e processo grupal. In: Kurcgant $P$, coordenadora. gerenciamento em enfermagem. Rio de Janeiro (RJ): Guanabara-Koogan; 2005. p. 108-24.

21. Ministério da Saúde (BR). Política nacional de atenção básica. Brasília (DF): Ministério da Saúde; 2006. 